\title{
A Novel Approach for Groundwater Budgeting Using GIS in a Part of Pondicherry Region, India
}

\author{
Sivaraman Pethaperumal ${ }^{2}$, Sabarathinam Chidambaram ${ }^{1}$, Kandasamy Vijayaragavan ${ }^{1}$, \\ Mohan Viswanathan Prasanna ${ }^{3}$, Kannan Anandavel ${ }^{2}$, Ulaganathan Karmegam ${ }^{1}$, \\ Ramachandran Manivannan ${ }^{1}$, Paluchamy Anandhan ${ }^{1}$, Kesari Tirumalesh $^{4}$ \\ ${ }^{1}$ Department of Earth Sciences, Annamalai University, Annamalai Nagar, India \\ ${ }^{2}$ State Groundwater Unit and Soil Conservation, Department of Agriculture, Pondicherry, India \\ ${ }^{3}$ School of Engineering and Science, Department of Applied Geology, Curtin University of Technology, \\ Sarawak, Malaysia \\ ${ }^{4}$ Scientist D, Isotope Hydrology Division, BARC, Mumbai, India \\ E-mail:chidambaram_s@rediffmail.com \\ Received March 23, 2010; revised April 23, 2010; accepted May 6, 2010
}

\begin{abstract}
The over extraction of groundwater from the coastal aquifers, result in reduction of groundwater resource and lowering of water level. In general, the depletion of groundwater level enhances the landward migration of saltwater wedge. Pondicherry is one such region with recent alluvium as the major formation. Since the study area forms a part of the coastal aquifer system this behaves as a fragile ecosystem. The present study has been attempted to calculate the extraction of water and to estimate the amount of recharge into this alluvial aquifer by using groundwater level variations. The monthly water level fluctuation was observed during the study period (2000-2002) in eighteen locations. The maximum rise in groundwater level observed during 2000 was considered as the initial water level for the study and the subsequent decline in water level (draw down) was monitored monthly until the rising trend was noted. This indicates the fall in water level due to extraction. Later keeping the deepest draw down as the initial value increasing water level trend was studied until there was a notice of decline in groundwater level. This indicates as the rise in water level due to recharge. This method of observation carried out at a single location was adopted for all eighteen locations. The spatial representation of these data for eighteen locations were carried out by using GIS and the area occupied by different groundwater level contours were calculated and the amount of water withdrawn/recharged was estimated. The maximum recharge was noted in the central and the northern part of the study area when compared to the other regions. Similarly, the maximum discharge was noted in the northern and the southern part of the study area during the study period.
\end{abstract}

Keywords: Water Level, Recharge, Groundwater Budget, GIS

\section{Introduction}

Groundwater is one of the most important and scarce commodity. Groundwater exists in the geological formations through which it can penetrate, be transmitted and stored beneath the surface. When the rate of infiltration is sufficient and the rocks are saturated to an appreciable thickness, then the groundwater becomes usable enough to yield useful supplies of water to wells, springs and stream. At present nearly $1 / 5$ th of all the water used in the world are obtained from the groundwater. Land use/ land cover pattern of Pondicherry and its surroundings were studied by using IRS 1C LISS III data [1]. The land use/land cover patterns were visually interpreted and di- gitized using ERDAS IMAGINE software. The study observed that agriculture area $(52.89 \%)$ is dominant in Pondicherry and its surroundings, followed by settlement with vegetation $(18.35 \%)$. The dependency of groundwater for the agricultural purpose has considerably increased in the recent past. Nearly about $80 \%$ of groundwater is used for agriculture. The quantification of the groundwater resources has become essential for water management. There are differebt methods for assessing the rate of recharge e.g., by using stable isotope, tra- cer techniques, groundwater modeling (thangarajan et al.) etc. Aquifer recharge studies using different isotopes for determination of infiltration capacities, permeability and in delineation of aquifer, inter connection were studied 
by several authors [2-10]. An Indicator based model was described to assess and quantify the significance of vulnerability to salt water intrusion due to excessive groundwater withdrawal and also to analyze the impact of artificial recharge in minimizing the salt water intrusion for coastal aquifers [11]. A detailed study on the Pondicherry groundwater was also done by National Geophysical Research Institute Hyderabad [12] to estimate the areas of over exploitation and to derive water balance using geo-hydrological data. Groundwater utilization for agricultural intensification in the Pondicherry region was studied by CGWB [13]. A detailed study was also carried out by the State Groundwater Unit of Agriculture Department, Pondicherry [14] to augment the available groundwater resource. Since the available methods are sophisticated, time consuming and costly an alternate method for the assessment of groundwater recharge and discharge was attempted by using the available groundwater level and GIS technique. Visualization is a convenient and effective way to communicate complex information. Greater importance is being put on data visualization today, GIS is a leading technology in this movement. It has tremendous potential to affect a wide variety of fields in present day. Hence, an attempt has been made in this study to handle GIS technique for groundwater budgeting in this shallow alluvial aquifer of Pondicherry region using water level data.

\section{Study Area}

The study area is located $28 \mathrm{~km}$ in the North West part of Pondicherry region, it lies between latitudes of $11^{0} 50^{\prime} \mathrm{N}$ to $12^{\circ} 59^{\prime} \mathrm{N}$ and longitude of $70^{\circ} 35^{\prime} \mathrm{E}$ to $70^{\circ} 45^{\prime} \mathrm{E}$ (Figure 1). The study area falls in the survey of Indian top sheets of $58 \mathrm{M} / 10$. It geographically covers an extent of nearly 85 Sq.km. Groundwater of the study area occurs in alluvial aquifer under un-confined to semi-confined condition. The depth of the tube wells tapping this aquifer ranges between $25 \mathrm{~m}$ and $50 \mathrm{~m} \mathrm{bgl}$ (below ground level). The average annual fluctuation is around $7.50 \mathrm{~m}$. The studies [15] indicate that the transmissivity values of the aquifers is $275.4 \mathrm{~m}^{2} / \mathrm{d}$ at Madukarai in the west and is $770 \mathrm{~m}^{2} / \mathrm{d}$ at Thirukanji in the east.

\subsection{Geology}

The results of the shallow drilling in north of Pondicherry $[16,17]$ reveals the geology of the region. Later the Central Groundwater Board, Governement of India [18] brought out a detailed report on the groundwater survey and exploration in the Union Territory of Pondicherry. In general the geology of Pondicherry region ranges from Archean to recent alluvium. The recent formation in the region is represented by Laterite and alluvium,

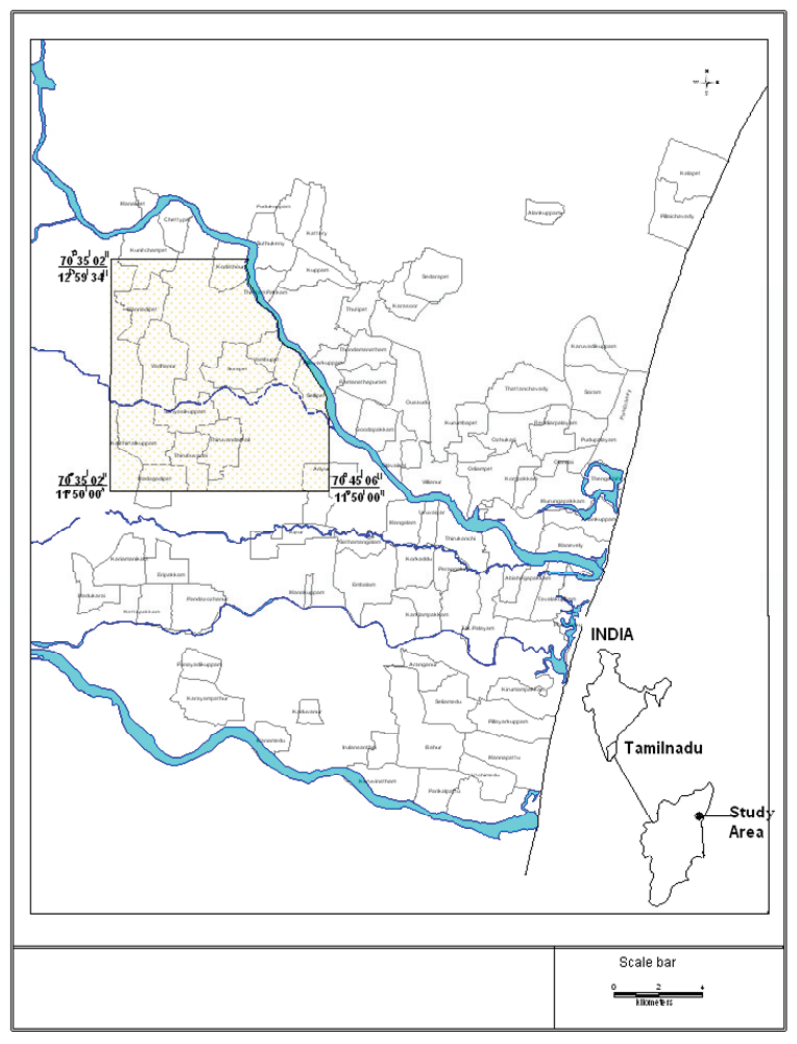

Figure 1. Location map of the study area.

Laterite occurs as thin cap over the Cuddalore formation. Thickalluvial deposits are built up along the course of Pennaiar and Gingee rivers. The study area falls in this region and is completely covered by alluvium.

\section{Methodology}

Water level data for the past 14 years were observed and the study was conducted for a period of three years (2000-2002).

\subsection{Discharge}

In the year 2000 the monthly water level data was studied and the minimum drawdown level of groundwater was noted. This is taken as the initial reading $\left(\mathrm{I}_{\mathrm{L}}\right)$. Similarly, in the simultaneous year (2001) the maximum drawdown level of groundwater is noted $\left(\mathrm{D}_{\mathrm{L}}\right)$. The difference between this two groundwater levels gives the discharge in region $\left(I_{L} \sim D_{L}\right)$, using this phenomenon difference in water level was calculated for the different location in the study area. The rate of discharge $\left(D_{R}\right)$ can be calculated by the difference between the initial water level $\left(\mathrm{I}_{\mathrm{L}}\right)$ and maximum drawdown level $\left(\mathrm{D}_{\mathrm{L}}\right)$ divided by the time taken for discharge $\left(\mathrm{D}_{\mathrm{T}}\right)$. 


$$
\mathrm{D}_{\mathrm{R}}=\frac{\mathrm{I}_{\mathrm{L}} \sim \mathrm{D}_{\mathrm{L}}}{\mathrm{D}_{\mathrm{T}}}
$$

\subsection{Recharge}

In the year 2001, the maximum drawdown level of groundwater level $\left(\mathrm{D}_{\mathrm{L}}\right)$ was noted and the subsequent rise in monthly water level was noted till the deviation of water level decrease was identified. This level of risen water table $\left(\mathrm{R}_{\mathrm{L}}\right)$ is the recharge level. The difference between this two groundwater levels gives the recharge (R). The time taken for the recharge water level from the maximum draw down level can be calculated $\left(\mathrm{R}_{\mathrm{T}}\right)$. The rates and recharge $\left(R_{R}\right)$ is given by,

$$
\begin{gathered}
R_{R}=\frac{R}{R_{T}} \\
R=\left(D_{L} \sim R_{L}\right)
\end{gathered}
$$

The study pertains to a part of Pondicherry region covered by unconfined aquifers in alluvial formation. The water level data for the three years were analyzed as per the methodology mentioned above.

\subsection{GIS}

Map info (Ver.7.8) GIS software along with Vertical Mapper was used to spatially distribute the water level data in order to locate the region of maximum discharge and recharge. The rate of recharge and discharge were also calculated and spatially plotted on the map. GIS helps to approximately calculate the area of recharge and discharge falling in different contour intervals.

\section{Result and Discussion}

The initial (shallow) and maximum (deeper) water levels for each location were identified (Table 1). The shallow water table was identified during February in most of the locations. Similarly, the maximum draw down (DD) level was noted during the period of September. The maximum discharge (Table 1) was noted at the Kodukkur region, it lies in the northern part of the study area. The rate of the discharge is $13.97 \mathrm{~m}$ in 7 months, i.e., about $1.99 \mathrm{~m} /$ month. In general the subsurface water flow is from the north to the south, more over there are number of agricultural fields located in this region and the main crop cultivated is paddy. The alluvial plain here is generally a monotonous with slope ranging from $1 \mathrm{~m}$ to $3 \mathrm{~m}$. The lands in this plain are intensively cultivated throughout the year. The minimum discharge was noted at the V. Nerkunam region it is located in the eastern part of study area, the discharge rate is $0.69 \mathrm{~m}$ in 7 months, i.e., about $0.098 \mathrm{~m} / \mathrm{month}$. The average discharge level of the study area is $6 \mathrm{~m}$ and the average rate of discharge is $0.45 \mathrm{~m}$. The maximum time taken for the discharge in the study area is 19 months. Assessment of groundwater resources of Pondicherry region by Sukhija [19] estimated the groundwater inputs and annual recharge is due to rainfall, return flow from agricultural fields, seepage from tanks, canals and groundwater in-flow. The general overview of groundwater and the water level changes were discussed in the CGWB report [20]. Besides the rivers and major canals, there are depressions acting as storage tanks which are spread all over the terrain to serve as surface water reservoirs.

From the recharge status (Table 2) of the study area, the maximum recharge is noted at the Kodukkur region, it lies in the northern part of the study area. The recharge is $14.19 \mathrm{~m}$ for the particular year and the rate of recharge is 1.18 /month., the minimum recharge is noted at the Sompet region, it is located in the western part of the study area. The recharge of this region is about $0.4 \mathrm{~m}$ for four months; the rate of recharge is $0.10 \mathrm{~m} / \mathrm{month}$. A study of the distribution of rainfall reveals (Pethaperuaml 2008) that there is a decrease in the rainfall from east to west, about $1300 \mathrm{~mm}$ near the coast to $1100 \mathrm{~mm}$ in the west. The average recharge level is $2.6 \mathrm{~m}$, in the Vampupet, Kalitheampattu and Rajaputhrapallayam region. The average rate of recharge of the study area is $0.58 \mathrm{~m} /$ month. The northern part of the study area shows high rate of recharge due to three reasons; 1) agricultural return flow; 2) direct recharge from the river Gingee and 3) flow of groundwater from the adjacent areas.

\subsection{Spatial Distribution of Discharge}

Initially the difference between the shallow and deeper water level of the study area helps to identify the discharge level. A contour map (Figure 2) was derived out for this discharge level data (Table 3), depicting three categories of discharge as maximum, minimum and moderate. All categories discussed in this paper are in order to differentiat the available data. The contour interval ranging form $10.69 \mathrm{~m}$ to $13.97 \mathrm{~m}$ indicates maximum discharge region in the study area, which falls near Kodukkur, the spatial extent of this maximum discharge covers 1.79 sq.km. The contour interval ranging from $0.69 \mathrm{~m}$ to $5.69 \mathrm{~m}$, indicates minimum discharge regions in the study area, with a spatial extent of 51.22 sq.km. The medium discharge level was identified to have a spatial extent of 31.99 sq.km lying between contours $5.69-10.69 \mathrm{~m}$.

\subsubsection{Spatial Distribution of Rate of Discharge}

The contour map for rate of discharge (Figure 3) shows four different categories (Table 4) of which the very high discharge rate is noted in Kodukkur covering an area of about 1.28 sq.km. The low discharge rate covers about $90 \%$ of the study area with a spatial extent of about 
Table 1. Discharge status by using relative water level (2000-2001).

\begin{tabular}{|c|c|c|c|c|c|c|c|}
\hline \multirow{2}{*}{ Village } & \multicolumn{2}{|c|}{ Water Level } & \multicolumn{2}{|c|}{ Difference } & \multirow{2}{*}{$\begin{array}{l}\text { Rate } \\
\text { Month }\end{array}$} & \multicolumn{2}{|c|}{ Location } \\
\hline & initial (m) & MAX.DD (m) & Level & Month & & $\mathrm{X}$ & $\mathrm{Y}$ \\
\hline Mannadipet & 22.8 (Feb. 2k) & 29.95 (Sep. 01) & 7.15 & 19 & 0.3763 & 79.6251 & 11.9865 \\
\hline Thirukkanur & 23.65 (Feb.2k) & 28.7(Sep.01) & 5.05 & 19 & 0.2658 & 79.6357 & 11.9871 \\
\hline Sompet & 23.6 (Feb.2k) & 29.1 (Dec. 01) & 5.5 & 22 & 0.2500 & 79.6328 & 11.9731 \\
\hline Kudathur & 22 (Jan. 2k) & 29.1 (Dec. 01) & 7.1 & 12 & 0.5917 & 79.66 & 11.9913 \\
\hline Vambupet & 17.75 (Feb.2k) & 22.2 (Sep. 01) & 4.45 & 19 & 0.2342 & 79.6803 & 11.9646 \\
\hline Sellipet & 11.1 (Feb. 2k) & 18.1 (Sep.01) & 7 & 19 & 0.3684 & 79.7004 & 11.9507 \\
\hline Sagadapet & 22.15 (Oct. 2k) & 27.75 (Sep. 01) & 5.6 & 11 & 0.5090 & 79.6552 & 11.9444 \\
\hline Kalitheerthalkuppam & 8.65 (Feb. 2k) & 15.95 (Sep. 01) & 7.3 & 19 & 0.3842 & 79.6281 & 11.9233 \\
\hline Madagadipet & 8.5 (Feb. 2k) & 17.45 (Sep. 01) & 8.95 & 19 & 0.4711 & 79.6363 & 11.9192 \\
\hline Thirubuvanai & 6.2 (Feb. 2k) & 12.85 (Sep. 01) & 6.65 & 19 & 0.3500 & 79.6506 & 11.9161 \\
\hline Thiruvandarkoil & 7.85 (Oct. 2k) & 17.3 (Sep. 01) & 9.45 & 11 & 0.8591 & 79.6591 & 11.9171 \\
\hline Sorapet & $28.35(\operatorname{Jan} .2 \mathrm{k})$ & 33.3 (Dec. 01) & 4.95 & 12 & 0.4125 & 79.6648 & 11.9537 \\
\hline Rajaputrapalaym & 20.13 (Feb.2k) & 24.47 (Sep. 01) & 4.34 & 7 & 0.6200 & 79.6877 & 11.9343 \\
\hline Azhiyur & 17.52 (Sep.2k) & 22.21 (Sep. 01) & 4.69 & 12 & 0.3908 & 79.6672 & 11.9121 \\
\hline Kalithirampattu & 17.8 (Feb. $2 \mathrm{k})$ & 21.42 (Sep. 01) & 3.62 & 7 & 0.5171 & 79.6878 & 11.6596 \\
\hline V. Nerkunam & 21.33 (Feb.2k) & 22.02 (Spe. 01) & 0.69 & 7 & 0.0986 & 79.6724 & 11.9766 \\
\hline Kodukkur & $10.23($ Feb.2k) & 24.15 (Sep. 01) & 13.97 & 7 & 1.9957 & 79.6514 & 11.9962 \\
\hline Madurapakkam & $22.25($ Sep. $2 \mathrm{k})$ & 25.64 (Sep. 01) & 3.39 & 12 & 0.2825 & 79.621 & 11.9951 \\
\hline
\end{tabular}

Table 2. Recharge status by using relative water level (2001-2002).

\begin{tabular}{|c|c|c|c|c|c|c|c|}
\hline \multirow{2}{*}{ V illag e } & \multicolumn{2}{|c|}{ W a ter Leve 1} & \multicolumn{2}{|c|}{ D ifference } & \multirow{2}{*}{$\frac{\text { Rate }}{\text { M on th }}$} & \multicolumn{2}{|c|}{ Location } \\
\hline & $\operatorname{Max}(\mathrm{m})$ & $M$ in (m ) & Leve 1 & Month & & $\mathrm{X}$ & $\mathrm{Y}$ \\
\hline M annad ipet & 29.95 (Sep.01) & 28.3 (Ap.02) & 1.65 & 7 & 0.2357 & 79.6251 & 11.9865 \\
\hline Th irukkanur & $28.7($ S ep.01) & 27 (Feb.02) & 1.7 & 5 & 0.3400 & 79.6357 & 11.9871 \\
\hline Som pet & 29.1 (D ec. 01$)$ & 28.7 (Ap. 02) & 0.4 & 4 & 0.1000 & 79.6328 & 11.9731 \\
\hline Kudathur & 29.1 (D ec. 01$)$ & 23.65 (Feb. 02) & 5.45 & 2 & 2.725 & 79.66 & 11.9913 \\
\hline Vam bupet & 22.2 (S ep.01) & 19.6 (Feb. 02) & 2.6 & 5 & 0.52 & 79.6803 & 11.9646 \\
\hline S e llip et & 18.1 (S ep.01) & 14.9 (Feb. 02) & 3.2 & 5 & 0.64 & 79.7004 & 11.9507 \\
\hline Sagadapet & 27.75 (Sep.01) & 26.65 (Feb. 02) & 1.1 & 5 & 0.22 & 79.6552 & 11.9444 \\
\hline K.kuppam & 17 (Sep. 01) & $15.95($ Feb. 02) & 1.05 & 5 & 0.21 & 79.6281 & 11.9233 \\
\hline M adagad ipet & 17.65 (Sep.01) & 17.45 (Feb. 02) & 0.2 & 5 & 0.04 & 79.6363 & 11.9192 \\
\hline Th irubuvanai & 13.8 (S ep. 01$)$ & 12.85 (Feb. 02) & 0.95 & 5 & 0.19 & 79.6506 & 11.9161 \\
\hline Th iru vand arko il & 17.3 (S ep. 01) & 16.3 (Feb. 02) & 1 & 5 & 0.2 & 79.6591 & 11.9171 \\
\hline Sorapet & $33.3(\mathbb{D}$ ec. 01$)$ & 29.4 (Feb. 02) & 3.9 & 2 & 1.95 & 79.6648 & 11.9537 \\
\hline Ra japu trap a laym & 24.47 (Sep.01) & 21.87 (Feb. 02) & 2.6 & 5 & 0.52 & 79.6877 & 11.9343 \\
\hline A zh iyur & 22.21 (Sep.01) & 18.71 (Feb. 02) & 3.5 & 5 & .7 & 79.6672 & 11.9121 \\
\hline Ka lith iram pattu & 21.42 (Sep.01) & 18.8 (Feb. 02) & 2.62 & 5 & 0.524 & 79.6878 & 11.6596 \\
\hline V. Nerkunam & 22.02 (Spe.01) & 21.54 (Feb. 02) & 0.48 & 5 & 0.096 & 79.6724 & 11.9766 \\
\hline Kodukkur & $24.15($ Sep. 01) & 9.96 (S ep.02) & 14.19 & 12 & 1.1825 & 79.6514 & 11.9962 \\
\hline M adurapakkam & 26.35 (S ep. 01) & 25.64 (Feb. 02) & 0.71 & 5 & 0.142 & 79.621 & 11.9951 \\
\hline
\end{tabular}


Table 3. Area occupied by difference rang of for discharge level relative water level.

\begin{tabular}{ccc}
\hline Categories & Ranges (m) & Area (Sq. Km) \\
\hline Minimum & $0.6961-5.6962$ & 51.2173 \\
Moderate & $5.6962-10.6962$ & 31.9969 \\
Maximum & $10.6962-13.9696$ & 1.7923 \\
\hline
\end{tabular}

Table 4. Area occupied by different ranges of for rate of discharge relative water level.

\begin{tabular}{|c|c|c|}
\hline Categories & Ranges (m) & Area (Sq. Km) \\
\hline Low & $0.0988-0.5989$ & 73.4384 \\
\hline Medium & $0.5989-1.0989$ & 9.0898 \\
\hline High & $1.0989-1.5989$ & 1.2029 \\
\hline Very high & $1.5989-1.9956$ & 1.2768 \\
\hline
\end{tabular}

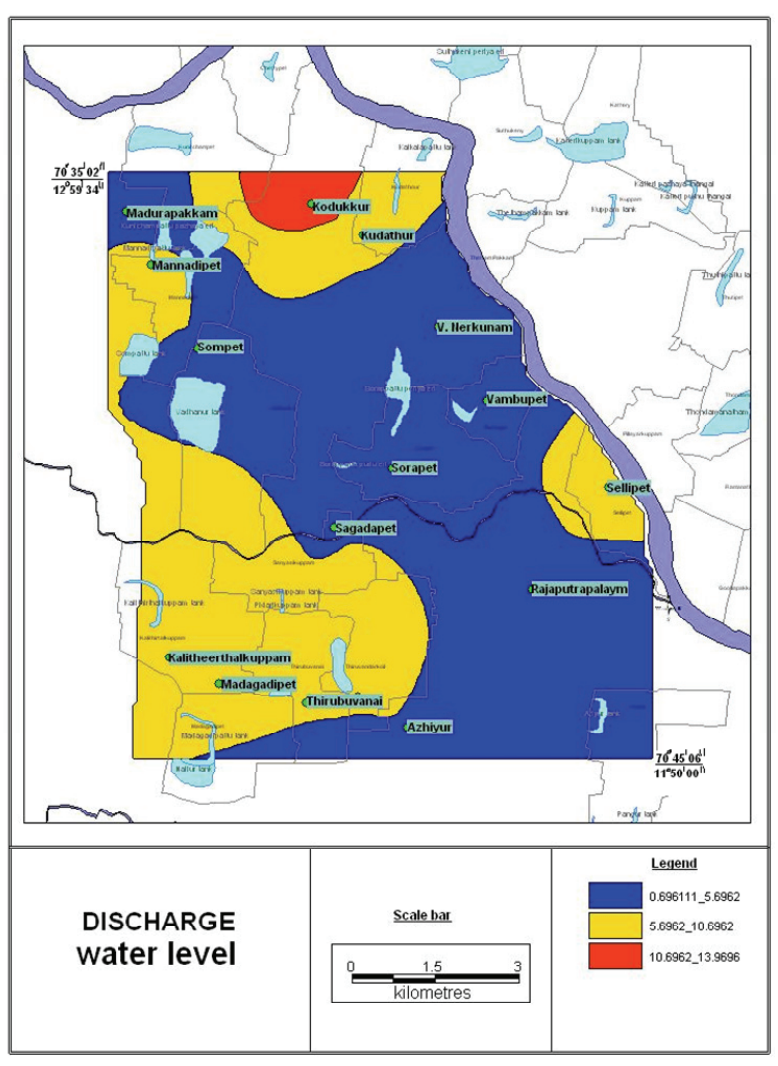

Figure 2. Contour map of discharge water level.

73.43 sq. $\mathrm{km}$. The rate of discharge of the remaining part of the study area falls in medium $(0.59-1.09 \mathrm{~m} / \mathrm{month})$ and high (1.09-1.59 m/month) category.

\subsection{Spatial Distribution of Recharge}

Difference between the maximum and minimum water level (Water Level Difference) helps to find the recharge. By using the recharge level data (Table 5) a contour map

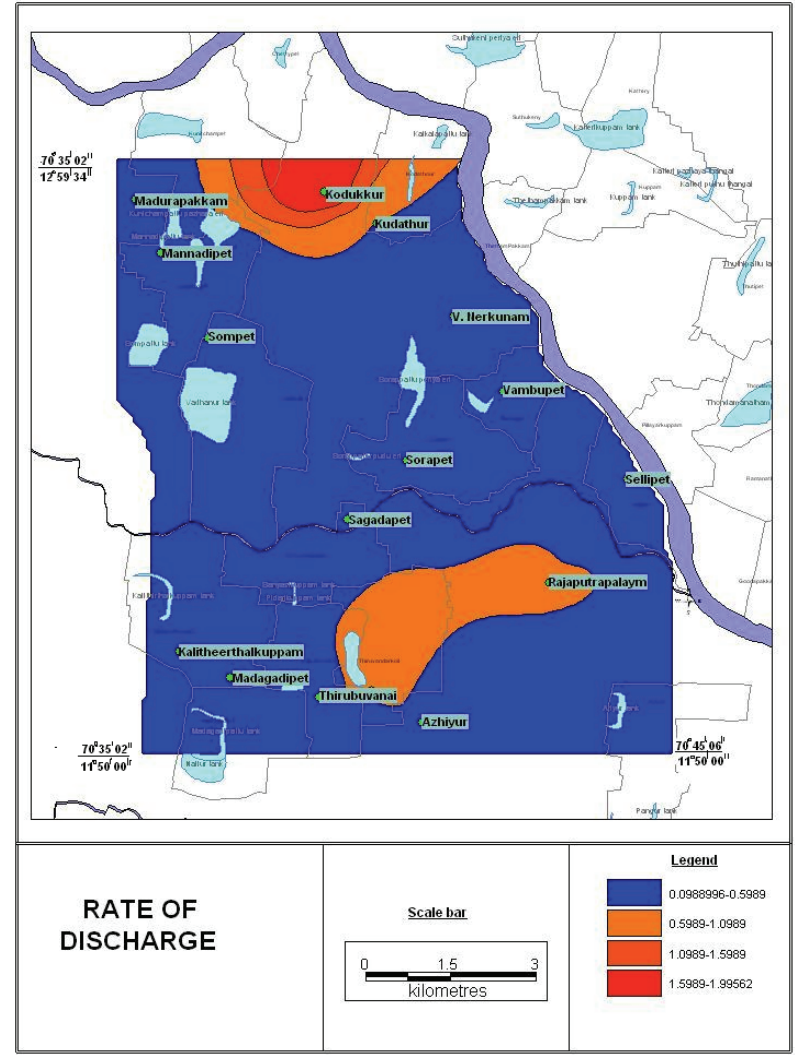

Figure 3. Contour map for rate of discharge.

was drawn (Figure 4) with three different categories as low, medium and high recharge. The high recharge was again noted at Kodukkur, it lies between 10.20-14.18 m contour. It is interesting to note that both high discharge and recharge are noted in the same region. Kodukkur region is dominated by groundwater dependent irrigation system for paddy cultivation. Hence higher rate of discharge is noted in this region but since the area is an alluvial terrain with good porosity the agricultural return 


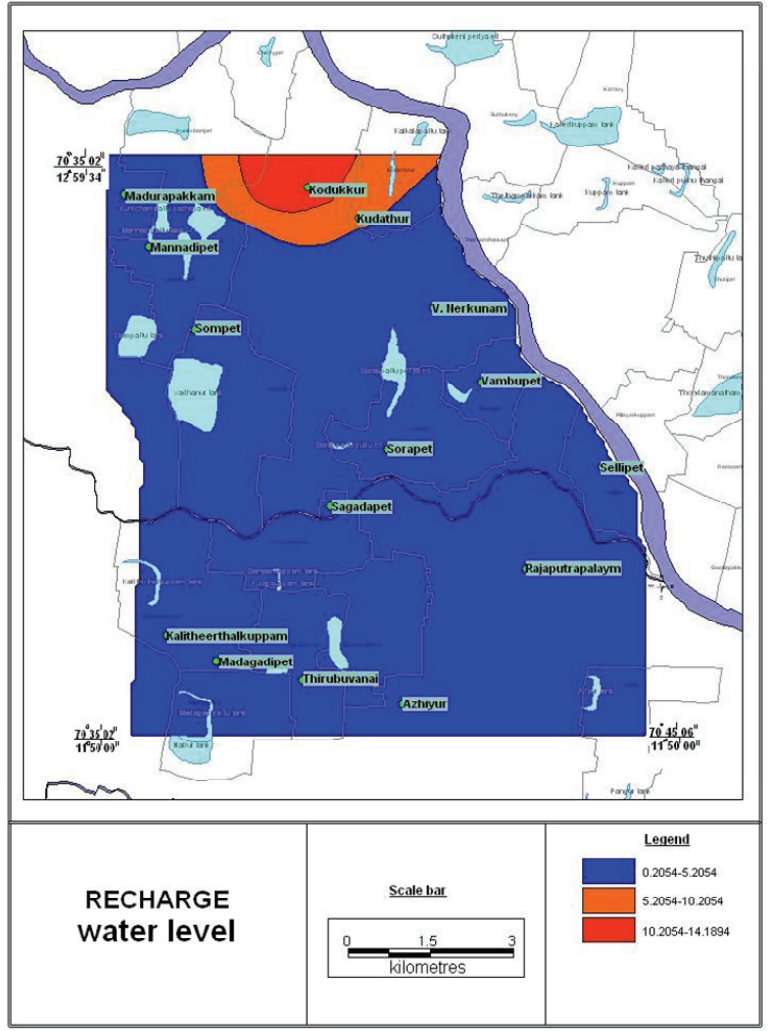

Figure 4. Map for recharged water level.

Table 5. Area occupied by different ranges of for recharge level relative water level (2002).

\begin{tabular}{ccc}
\hline Categories & Ranges $(\mathrm{m})$ & Area $(\mathrm{Sq} . \mathrm{Km})$ \\
\hline Low & $0.2054-5.254$ & 80.0144 \\
Medium & $5.254-$ & 3.3067 \\
& 10.2054 & \\
High & $10.2054-$ & 1.6844 \\
\hline
\end{tabular}

flow enhances the rate of recharge in this region. The spatial extent of this high recharge is 1.68 sq.km, the low recharge (Table 5) the study area falls between 0.20 to 5.20 $\mathrm{m}$ category, which covers an area of about 80.91 sq.km. The rest is occupied by the medium recharge region.

\subsubsection{Spatial Distribution of Rate of Recharge}

The calculated recharge rate was spatially plotted on a contour map (Figure 5) with six different categories (Table 6) like excellent, very good, good, moderate, poor and very poor. The Excellent recharge rate range between $2.54 \mathrm{~m} /$ month and $2.72 \mathrm{~m} /$ month. This is noted in Kodukkur and Sorapet villages, covering an area of 0.71 sq.km. Similarly, the Very poor recharge rate was found near Sompet, K. Kuppum, V. Nerkunam, Sagadapet and Rajaputra palayam villages, ranging between $0.041 \mathrm{~m} / \mathrm{month}$ and $0.54 \mathrm{~m} / \mathrm{month}$ which cover an area of 44.13 sq.km. The poor category ranges between 0.54
Table 6. Area occupied by different ranges of for rate of recharge relative water level.

\begin{tabular}{lll}
\hline Categories & Ranges $(\mathrm{m})$ & Area $(\mathrm{Sq} . \mathrm{Km})$ \\
\hline Very poor & $0.0411-0.5411$ & 44.1351 \\
Poor & $0.5411-1.0411$ & 28.2419 \\
Moderate & $1.0411-1.5411$ & 6.4208 \\
Good & $1.5411-2.0411$ & 3.36478 \\
Very good & $2.0411-2.5411$ & 2.1276 \\
excellent & $2.5411-2.7229$ & 0.7131 \\
\hline
\end{tabular}

$\mathrm{m} / \mathrm{month}$ and $1.04 \mathrm{~m} /$ month covering an area of 28.24 sq.km. Rest of the area falls in, moderate $(1.04-1.0 \mathrm{~m} /$ month), good (1.54-2.04 m/month) and very good (2.04 $-2.54 \mathrm{~m} / \mathrm{month}$ ) categories. The average rate of recharge in the study area is $1.38 \mathrm{~m} /$ month.

\subsection{Volume Estimation}

Based on the recharge and discharge contour maps, the mid point of the each contour range is multiplied with area lying between the contours, to derive the volume of the recharge/discharge area. This is in turn multiplied by the porosity of the formation (alluvium) to obtain the storage capacity of aquifer. If the porosity of the region is assumed to be $15 \%$, the amount of water withdrawn is $67208.30 \times 10^{3} \mathrm{~m}^{3}$ and the quantity of water recharged is $39374.26 \times 10^{3} \mathrm{~m}^{3}$. The rate of recharge was noticed to be higher in centre part of the study area at Sorapet.

The study shows that water level increases during monsoon period and decreases during post monsoon and summer. The discharge period is about 19 months on an average and the recharge is observed for a lesser interval of 5 month during the study period. Hence, it is noted that the duration of discharge is higher that the recharge. The estimated recharge volume also proves that the volume of the water recharged is almost half of the volume of discharge.

\section{Conclusions}

The variation in water level helps us to identify the difference in groundwater potential. The above study facilitates to spatially identify the regions with high discharge and good recharge. It also brings out the rate of recharge and discharge and therby to discriminate the regions with the above function. The study also reveals that the discharge and recharge is higher a one specific location which is mainly due to agricultural extraction and return flow respectively. This study also reveals a fact the though both the process takes place simultaneously in nature, there can be specific demarcation of period for discharge and recharge dominance. The discharge is noted for a longer period than the recharge is for a shorter period due the lesser availability of water. The spatial extent of the results will help the water managers to provide scientific solutions for the resource. So, the volume 
of the extraction and recharge in a particular area with the aid of GIS reduces the adhoc experimentation and this method is also less expensive. Hence the monthly water level data of a region along with GIS software can assist in evolving the maximum recharge and discharge regions along with the volume of the water recharged or discharged in a specific area.

\section{Acknowledgements}

The authors wish to express thank to the state groundwater unit and soil conservation, Pondicherry, BRNS for the financial support, and staff members in Department of Earth Sciences, Annamalai University for their cooperation.

\section{References}

[1] E. P. Nobi, R. Umamaheswari, C. Stella and T. Thangaradjou, "Land Use and Land Cover Assessment along Pondicherry and its Surroundings Using Indian Remote Sensing Satellite and GIS," American-Eurasian Journal of Scientific Research, Vol. 4, No. 2, 2009, pp. 54-58.

[2] V. P. Yakutseni, "Geology of Helium (Geologiya Geliya)," Nedra Publishing, Leningrad, 1968.

[3] T. Dincer, W. Almurin and V. Zimmerman, "Study of Infiltration and Recharge through the Sand Dunes in Arid Zones with Special Reference to the Stable Isotopes and Thermonuclear Tritium," Journal of Hydrology, Vol. 23, No. 12, 1974, pp. 79-109.

[4] V. I. Ferronsky, Ed, "Isotopes of Natural Waters," Nanka Publishing, Isotopiya Pairodnykhvod, Moscow, 1978.

[5] R. A. Downing, F. J. Pearson and D. D. Smith, "The Flow Mechanism in the Chalk Based on Radio-Isotope Analysis of Groundwater in the London Basin," Journal of Hydrology, Vol. 40, No. 1-2, 1979, pp. 67-83.

[6] C. Gaye and W. M. Edmunds, "Groundwater Recharges Estimation Using Chloride, Stable Isotopes and Tritium Profiler in the Sands of Northwestern Senegal," Environmental Geology, Vol. 127, 1996, pp. 246-251.

[7] G. B. Allison, "A Review of Some of the Physical, Chemical and Isotope Techniques Available for Estimating Groundwater Recharge," Proceedings of NATO Workshop on Estimation of Natural Recharge of Groundwater, Antalaya Turkey, 1987, pp. 49-72.

[8] V. S. Kovalevsky and V. L. Zlobina, "Helium Survey for Delineation Areas of Karst - Suffosion Processes Caused by High-Rate Groundwater Withdrawal," Environmental Geology Water Sciences, Vol. 10, No. 2, 1987, pp. 89-94.
[9] B. S. Sukhija, D. V. Reddy, P. Nagabushanam, S. Hussain and V. Y. Giri, "The Use of Environmental Isotopes and Chloride as Natural Tracers to Investigate the Effects of Depressurization of a Coastal Aquifer for Lignite Mining, India," Hydrology Journal, Vol. 4, No. 2, 1996, pp. 70-87.

[10] M. F. Abu-Taleb, "The Use of Infiltration Field Tests for Groundwater Artificial Recharge," Environmental Geology, Vol. 37, No. 1-2, 1999, pp. 64-71.

[11] V. Lenin, K. Sundaram, G. Dinesh, G. Ravikumar and D. Govindarajalu, "Vulnerability Assessment of Seawater Intrusion and Effect of Artificial Recharge in Pondicherry," Indian Journal of Science and Technology, Vol. 1, No. 7, 2008, pp. 7-125.

[12] B. S. Sukhija, D. V. Reddy and I. Vasanthakumar Reddy, "Study of Ground Water Resources of Pondicherry and its Environs," 1987, pp. 3-151.

[13] M. Suresh, "Ground Utilization for Agricultural Intensification, A Case Study from Pondicherry," India with Reference to Sustainability and Equity, Agricultural University of Norway, 1996.

[14] State Ground Water Unit of Agriculture Department, "Tank Rehabilitation Project Pondicherry," Technical and Administrative Provisions, Public Works Department, Government of Pondicherry, Pondicherry, 1996.

[15] Central Ground Water Board (CGWB), "Groundwater Resource and Development Prospects in Pondicharry Region," Union Territory of Pondicherry, Vol. 19, No. 1-2, 1993, pp. 59-63.

[16] K. M. Nair and V. P. Rao, "Result of Shallow Drilling in the Area North of Pondicherry," Unpublished, Oil and Natural Gas Corporation Limited Field Season Report of 1969-1970, 1971.

[17] V. P. Rao "Field Party," Oil and Natural Gas Corporation Limited, India, No. 6, 1972.

[18] K. V. Raghava Rao, K. V. J. R.Krupanidhi, G. Balasubramanian, P. R. Subramaninan and P. Natarajan, "Report on Groundwater Survey and Exploration in the Union Territory of Pondicherry and its Environs," Central Ground Water Board Report, India, 1976.

[19] B. S. Sukhija, D. V. Reddy and P. Nagabhushaman, "Isotopic Fingerprints of Paleoclimates during the Last 30000 Years in Deep Confined Groundwaters of Southern India," Quartern Research, Vol. 50, No. 3, 1998, pp. 252 260.

[20] P. Natarajan, "Ground Water Resources and Development Prospects in Pondicherry Region, Union Territory of Pondicherry," Central Ground Water Board Report, August 1993, pp. 1-41. 